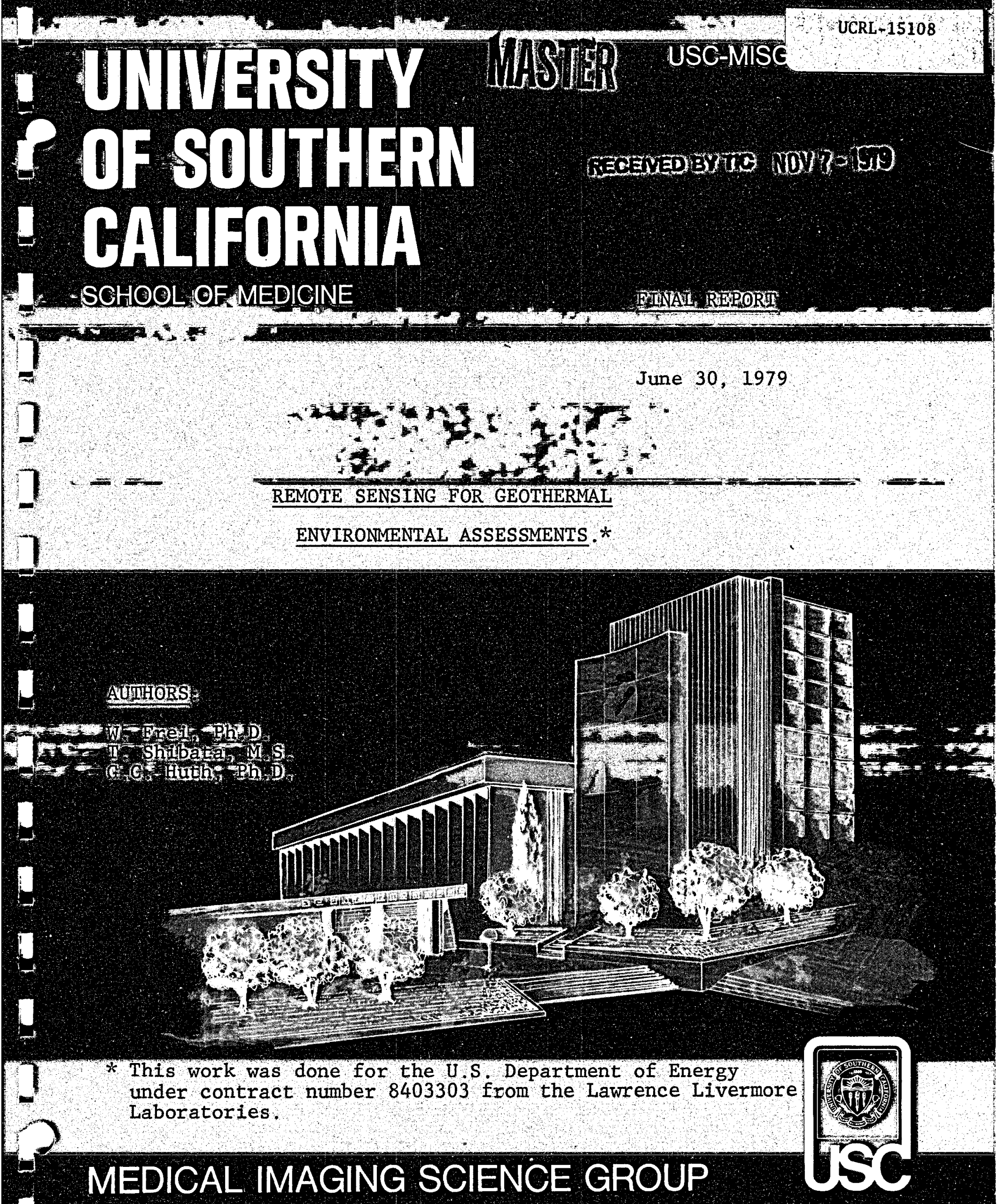




\section{DISCLAIMER}

This report was prepared as an account of work sponsored by an agency of the United States Government. Neither the United States Government nor any agency Thereof, nor any of their employees, makes any warranty, express or implied, or assumes any legal liability or responsibility for the accuracy, completeness, or usefulness of any information, apparatus, product, or process disclosed, or represents that its use would not infringe privately owned rights. Reference herein to any specific commercial product, process, or service by trade name, trademark, manufacturer, or otherwise does not necessarily constitute or imply its endorsement, recommendation, or favoring by the United States Government or any agency thereof. The views and opinions of authors expressed herein do not necessarily state or reflect those of the United States Government or any agency thereof. 


\section{DISCLAIMER}

Portions of this document may be illegible in electronic image products. Images are produced from the best available original document. 


\title{
REMOTE SENSING FOR GEOTHERMAL
}

ENVIRONMENTAL ASSESSMENTS *

$$
\text { P.0. } 8403303
$$

\section{Final Report}

By W. Frei, T. Shibata, G.C. Huth

\author{
Medical Imaging Sciences Group \\ $\checkmark$ liniversity of Southern California \\ 4676 Admiralty Way \\ $95^{9914}$
}

Marina Del Rey, CA 90291

June 30,1979

* This work was done for the U.S. Department of Energy under contract number 8403303 from the Iawrence Livermore Laboratories.

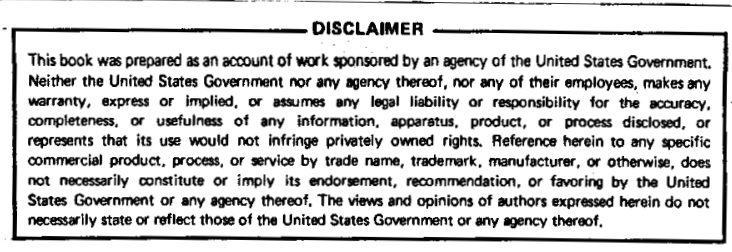




\section{ABSTRACT}

This report examines the role of remote sensing in the context of the Environmental Assessment Studies conducted by the U.S. Department of Energy.

Particular attention has been paid to the exploitation, by computer analysis, of low altitude aerial photographs, which had been made available for this project.

One technique-change detection - developed during this project, has been found to be particularly useful, because it permits to detect environmental changes at a very early stage where it might escape detection on the ground. This technique, which has now been perfected to be usable on a routine basis, can thus provide a very effective environmental "early warning" capability.

Several examples are shown in known Geothermal Resource Areas (KGRA's) in the Imperial Valley and the Geysers, California, which lead us to the conclusion that remote sensing should become an essential tool for the DOE Environmental Assessment Studies. 


\section{CONTENTS}

\section{Introduction}

2. Remote Sensing for Environmental Assessments

3. Change Detection in Remotely Sensed Images

4. Image Matching for Change Detection

5. The Geyser Geothermal Project

6. Conclusions and outlook

7. Acknowledgements 


\section{INTRODUCTION.}

The present report describes the research on remote sensing for geothermal environmental assessment, performed by the Medical Imaging Sciences Group under contract from the Lawrence Livermore Laboratories.

This work is a part of a larger environmental effort, undertaken under the sponsorship of the U.S. Department of Energy, to understand and document the potential environmental impact of new energy technologies, and to establish guidelines for ecologically sound planning and regulation.

At the focus of interest are the experimental recovery processes for the exploitation of alternative energy resources, such as geothermal heat, oil extraction from shales, coal gassification and so forth.

As a result, the DOE environmental assessment studies are mainly research oriented, as opposed to routine compliance monitoring: adequate methodologies have to be elaborated to study the effects of new technologies upon new environments; existing baselines need to be carefully documented, in order to detect the earliest symptoms caused by small pilot plants; realistic projections must be made for large scale developments.

An example of such a global endeavor is given by the Imperial Valley Environmental Project (IVEP), which is managed by the Lawcence Livermore Laboratory. The Imperial Valley in California contains several known Geothermal Resource Areas (KGRA's), which could produce several thousands megawatts of electricity within a few decades. This region 
is also one of the richest agricultural areas of the country, where negative environmental impacts could have serious consequences. The IVEP was thus designed to combine an unprecedented baseline documentation with the closest scrutiny of the experimental geothermal sites for emissions and other effects.

The present work had been originally initiated under the auspices of the Imperial Valley Environmental Project, to determine wether computer processing of aerial photographs could reveal valuable environmental information. An early success, namely, the detection of previously unsuspected crop injury downwind from a geothermal venting test prompted further studies in the Imperial Valley and in the Geyser Geothermal Resources Area. The rationale, methods and results of this research are described below. 


\section{REMOTE SENSING FOR ENVIROMMENTAL ASSESSMENTS}

Remote sensing means, literally, taking measurements from a distance. In this context, we understand measurements of the ground and ground cover acquired by cameras and scanners aboard aircraft or satellites.

Remote sensing has a number of unique characteristics which make its contribution invaluable in a number of disciplines of the earth sciences such as agriculture, foresting, geology, hydrology and so forth. These characteristics which are also of particular interest in the protection of the environment, are the following: first, information can be gathered over large areas, including inaccessible areas, at once and at moderate cost. Secondly, sensors can be used that are sensitive to non-visual portions of the electromagnetic spectrum, notably the near and thermal infrared, but also at radar wavelengths, allowing the detection of effects that are otherwise invisible. A case in point is early vegetation stress, which manifests itself as a reduced reflectivity in the near infra-red portion of the spectrum, and which is easily detectable by color infra-red films ${ }^{(2)}$ (see figure 1). Thirdly, remotely sensed data can be processed and analyzed by computer, to automatically detect and Identify phenomena of interest, or to compile statistical data for comparative studies. Finally, remotely sensed data as well as processed data can be represented in pictorial form, which often provide the observer with additional clues contained in the shapes, patterns and their relations to known landmarks and terrain features. For instance, a trail of slightly reduced vegetation density downwind from some exhaust stack would be conspicuous because of its shape and location, whereas it might elude the observer on the ground, who is limited to a finite number of observations. 
1) \% Reflectance

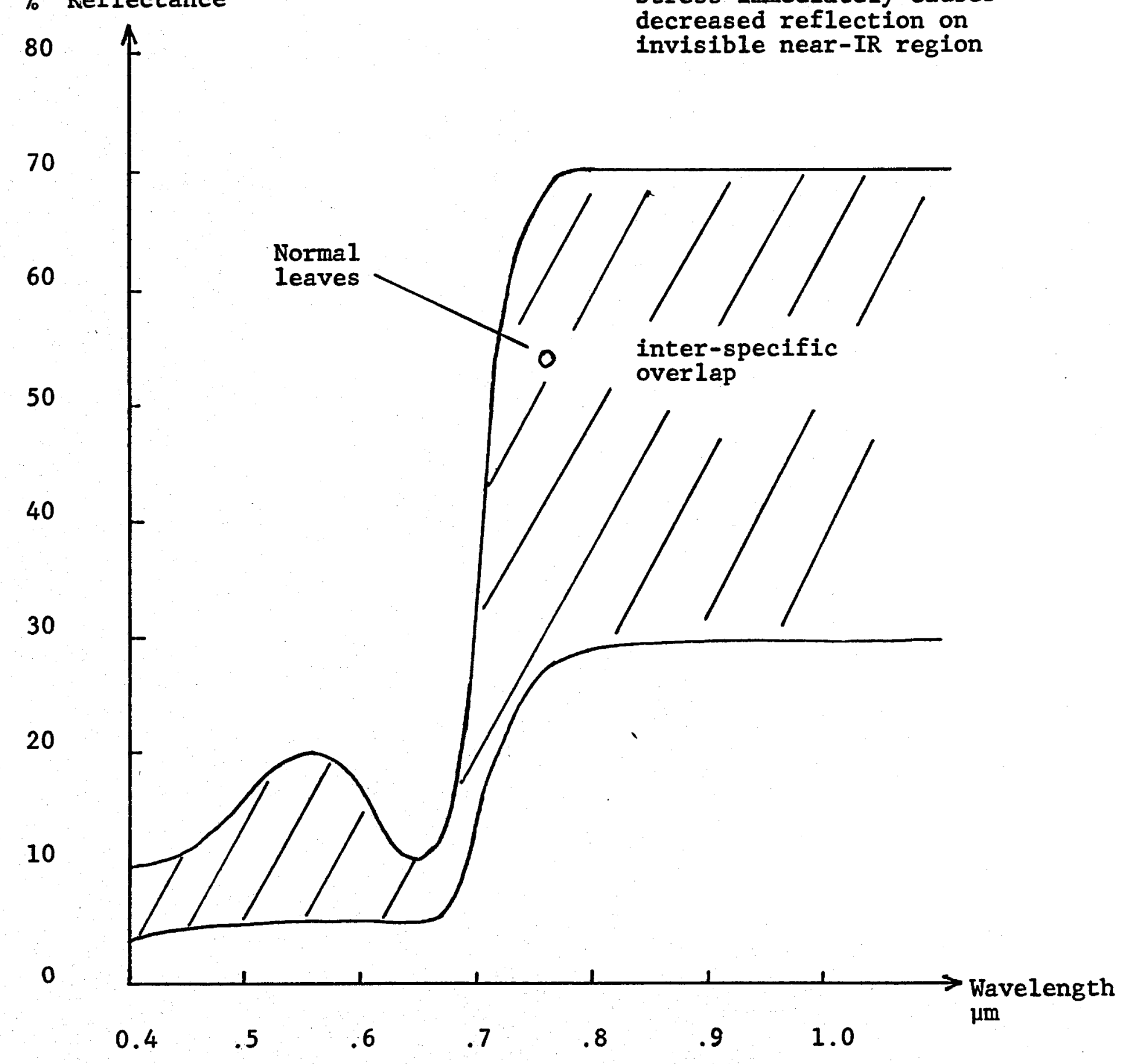

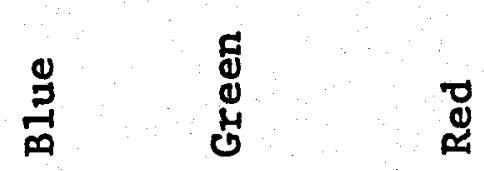

Visible near - infra-red

Figure 1 Reflectivity of normal leaves 
Remote sensing has naturally certain limitations as well. Although it can detect changes with great sensitivity it cannot in general provide a conclusiye proof as to the agents incolved, but rather suggest suggest suspicious factors which must be verified on the ground. Therefore, remote sensing acquires its full potential when coordinated with studies made on the ground, or in other words, when complemented with ground truth information.

It presently appears, in fact, that one of the foremost missions of remote sensing in environmental studies is the detection of suspicious changes, their preliminary analysis and interpretation, and the documentation of the environmental evolution over a period of time. Therefore, remote sensing is an important and adequate complement of the DOE environmental assessment studies. 


\section{CHANGE DETECTION IN REMOTELY}

SENSED IMAGES.

One of the salient properties of remotely sensed images is that otherwise invisible patterns on the ground become visible, providing cues and possibly early warnings of negative environmental impacts. Until recently however, aerial photographs have been mainly interpreted by visual inspection, restricting its use to documentation and qualitative, subjective interpretation. The major limitation of visual inspections is that the eye cannot "measure objectively" the physical quantities (grey levels, colors) contained in an image.

The advent of remote sensing satellite (LANDSAT, NOAA and military observation satellites) have spurred the development of computer processing and analysis techniques of remotely sensed images, which produce objective, quantative results, as well as greatly enhanced sensitivity to subtle changes. Most of these techniques can be applied to medium and low altitude aerial photographs by use of digital electrooptical scanners, which dissect aerial photographs into computer-compatible data for processing (Figure 2). In other instances, multispectral scanners similar to the sensing devices aboard satellites are flown on aircraft, directly producing computer-compatible data.

One technique of particular interest here, and originally developed by our group, under the auspices of the Imperial Valley Environmental project is change detection. This technique permits to detect and portray all the changes that have taken place between two successige photographic missions. 


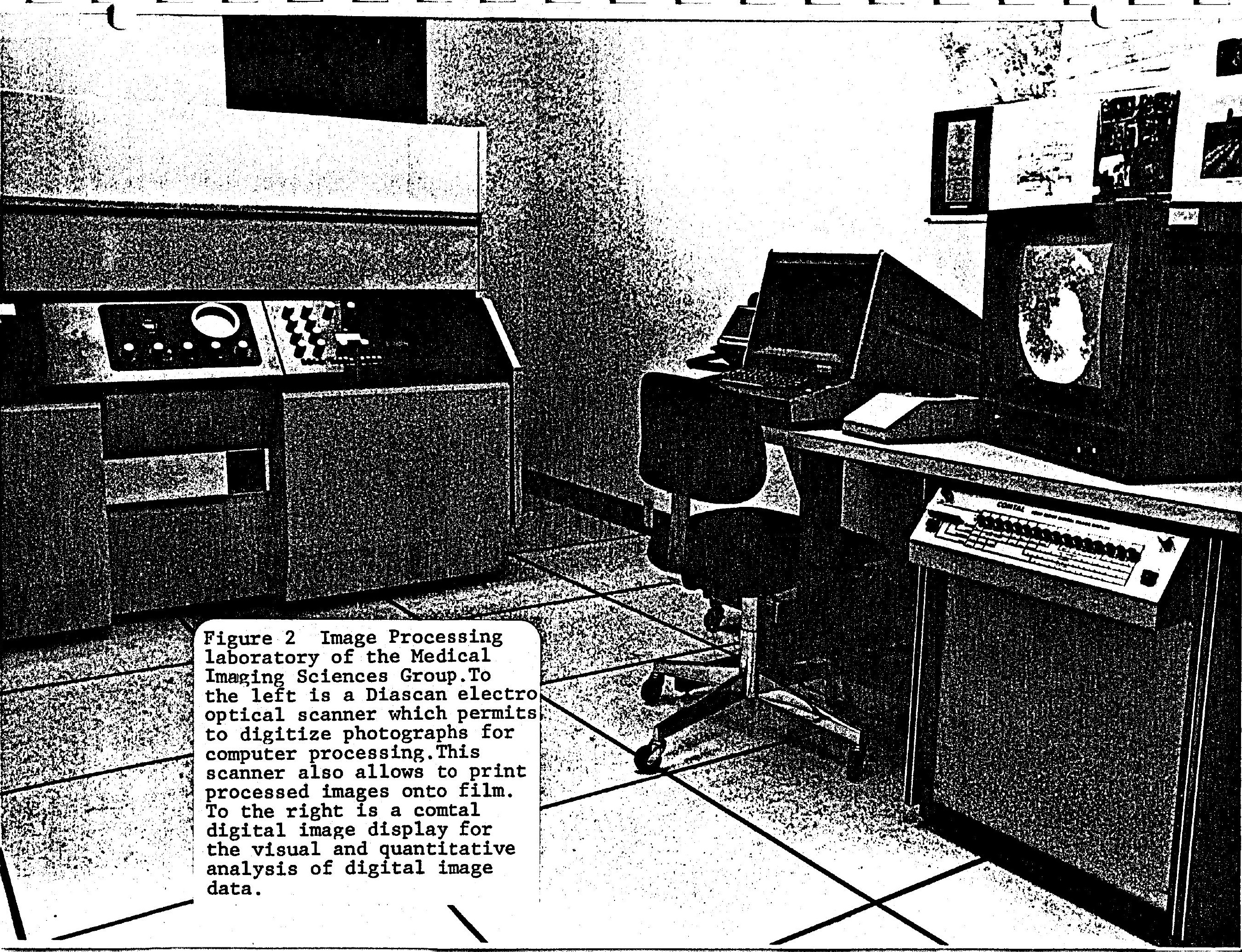


This technique, which is described in more detail below, can be summarized as follows: assume that we superimpose, point by point, two images taken at different times. Subtraction of the superimposed images then yield a new image or "change image", which portrays all the differences between the two original images, effectively extracting the information of interest. Using contextual information, an observer can interpret the patterns of change and trace them back to their origin. For example, an alfalfa field has been harvested, a cornfield has matured, a river has changed its course etc., or an area of forest downwind from a stack has not developed as much foliage as another similar forest area.

As a result, suspicious changes can be discovered at a very early stage and be immediately investigated, long before sizeable negative effects are allowed to develop. The following example illustrates the above proposition.

Figure 3 shows a pair of aerial photographs taken during and, respectively two weeks after a test. During the test, steam accidentally mixed with hot water spray was released for a short period of time into the atmosphere, causing some visible damage in the field downwind (wedge-shaped light area in Figure $3 \mathrm{~b}$ ). To the surprise of the investigating ecologist though, no damage whatsoever was visible in the neighboring field, also located within the estimated fall radius of the steam plume. It was concluded at that time that the different and more mature crop growing in the second field had simply survived the impact unharmed.

The images of Figure 3 were digitized, geometrically matched and subtracted from each other. The results, enhanced by histogram hyperbolization (3) is shown in Figure 4 

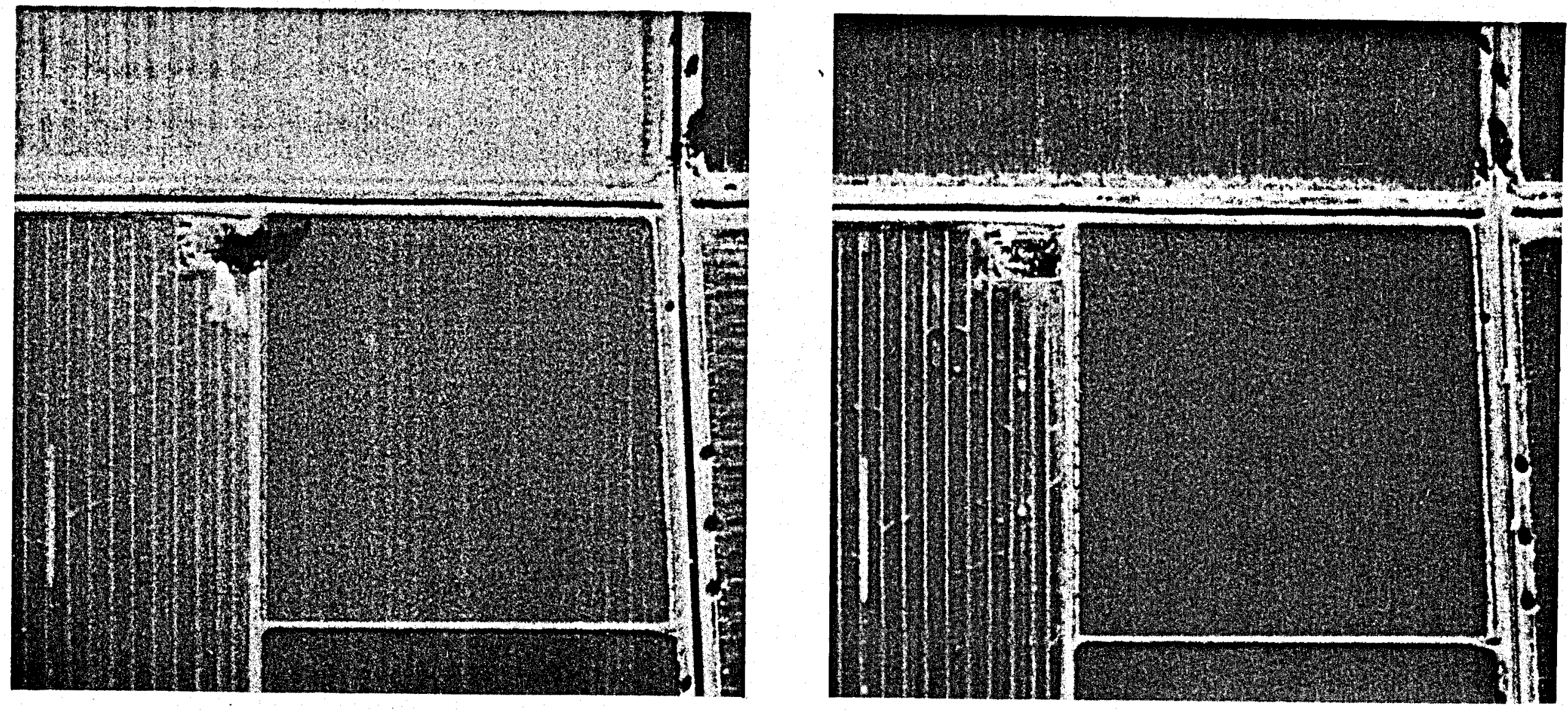

Figure 3

False color infra-red devial photographs of experimental geothermal well (reproduced here in black and white). To the left is the well under a venting test, and to the right is the same area two weeks after the test (see text). 
clearly revealing the expected pattern of affected vegetation. Although no effects had been visible in the second field shortly after the test, it has been later verified that the detected stress area failed to mature properly.

The success of this detection experiment can be attributed to three reasons. First of all, the reflectivity of stressed plants quickly drops in the near infrared, well before any change becomes noticeable in the visible spectrum (2). Secondly, The change is minute and its outlines are very smooth in the color infrared: photograph, a low contrast pattern which is particulerly difficult to discern visually (4). Thirdly, the pattern of change of Figure 4 is consistent with other documented evidence, such as wind speed and direction, and the analysis of samples taken in the visible affected area.

This example highlights the potential of change detection for the monitoring and protection of the environment: patterns of otherwise invisible relative changes can be detected, and when related to contextual information, provide clues or "advanced warning" to impending negative environmental impacts.

Additionally, such change imagery provides a sound basis for the planning of ecological studies on the ground, providing information as to where to focus such efforts.

The advantages of such a program are not limited to this, but are useful in a score of other ways, including site development and management, drainage control, fire damage evaluation, etc., to name a few. Secondly, a file of periodic aerial photographs provides a unique record over time, of the evolution of a region, including features that may have never been of interest at the time the images were taken. Such a file may prove invaluable for later reference and studies. We know of 


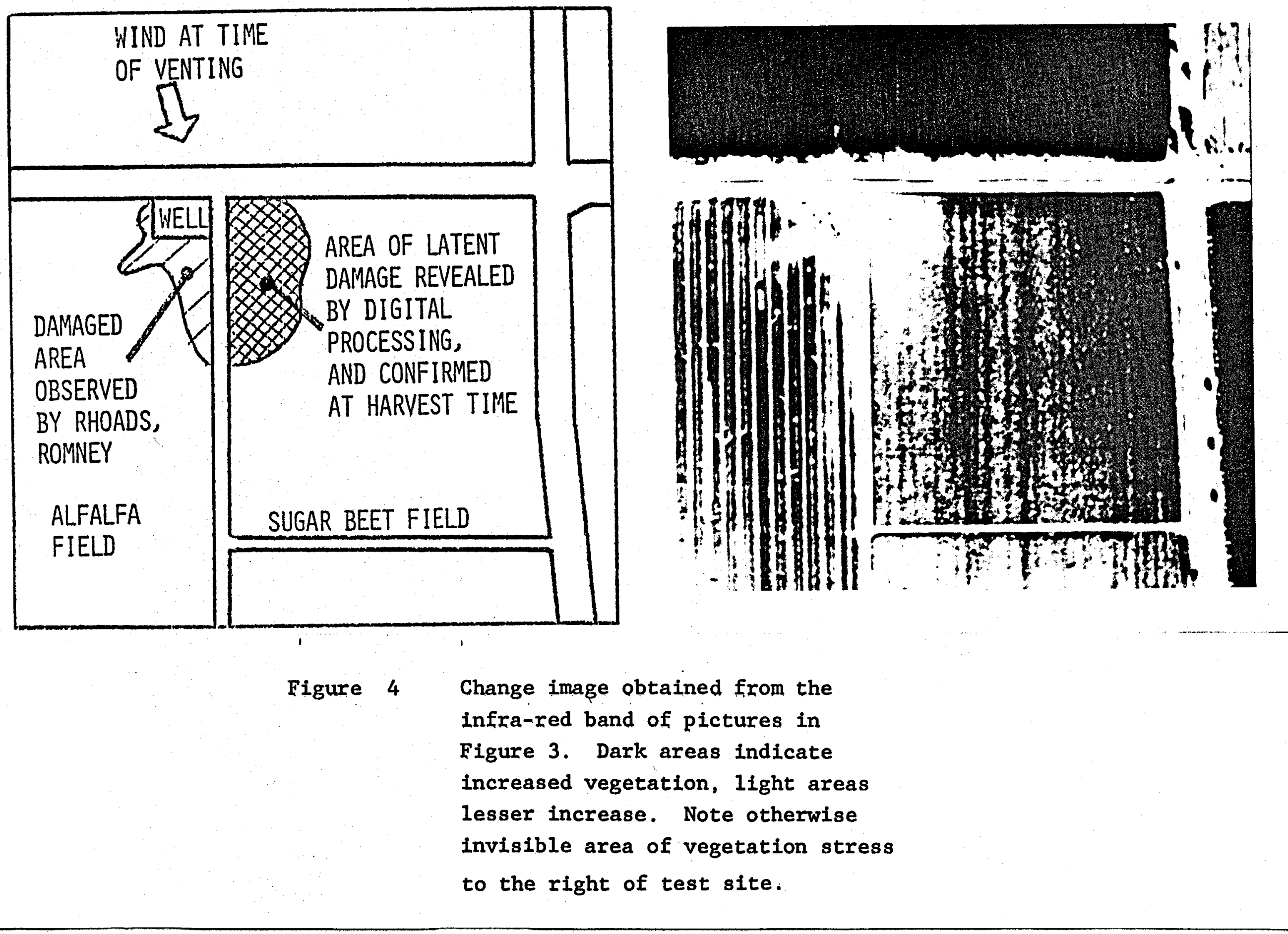


one instance for example, where litigation was effectively discouraged after the potential plaintiff was shown photographs taken at an earlier time, which established previous existence of the problem at issue. 
4. IMAGE MATCHING FOR CHANGE DETECTION.

Instrumental for change detection is the ability to match geometrically two images taken under different circumstances. This problem is particularly arduous in the present context, and its solution by our group has made change detection applicable to low altitude photography as used in the DOE environmental studies.

Consider a pair of aerial photographs taken of a mountainous terrain at two different times. If the camera is positioned differently (as may be expected), the projections are different (Figure 5) and the images will generally not match geometrically. The mismatch naturally decreases with increasing altitude, and at infinity, we would obtain an orthographic projection (Figure 5) that can be matched as if the scene were planar. A more practical way to generate orthographic projections is to reproject the images based upon the terrain elevations, which can be measured steroscopically.

If the terrain elevations are not known however, we can still obtain a reasonable match between the two images by some local matching techniques that can be visualized as follows: imagine that one image is printed on an ideal rubber sheet and the other one on a rigid support. The images could now be matched by pinning the rubber sheet onto the rigid support, driving the pins through corresponding image landmarks. Increase the number of pins and the match becomes more accurate, except for discontinuities around areas that are occluded in one view (the area between points $B$ and $C$ in Figure 5).

Theoretically, rubber sheet distortion can be realized 


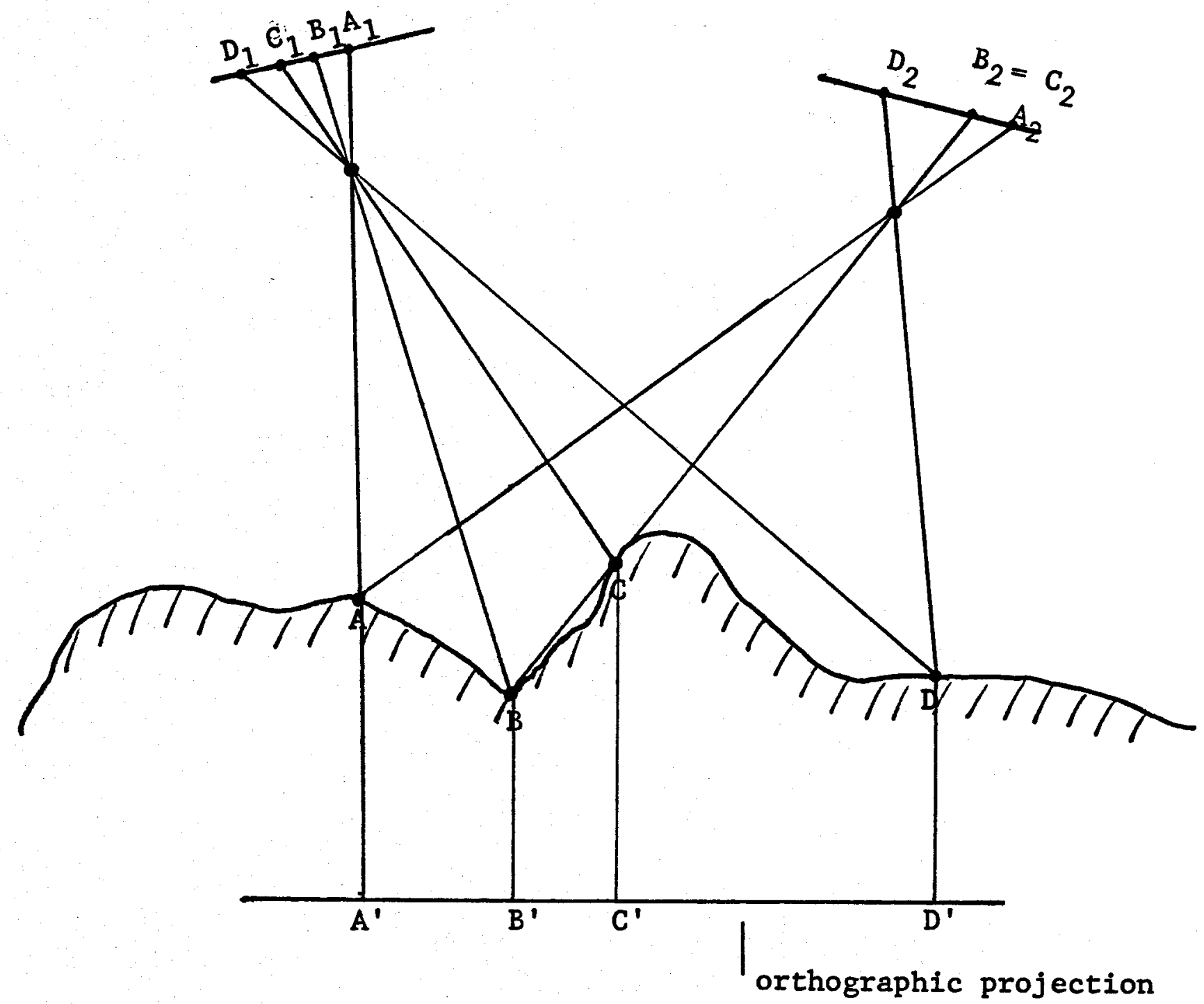

Figure 5 Two different aerial yiews and an orthographic projection of the same terrain. Note the relative geometric distortions. 
as follows: determine the coordinates (Xi, $\mathrm{Yi}$ ) in image $\mathrm{A}$ and $(U i, V i)$ in image $B(i=1, \ldots n)$, of corresponding landmarks (also called control points). Then, find a pair of functions $U(x, y)$ and $V(x, y)$ such that $U(X i, Y i)=V i$ and $\mathrm{V}(\mathrm{XI}, \mathrm{Yi})=\mathrm{Vi}$. For any point in image $A$, we can now find the corresponding coordinates in image $B$, and since these coordinates are generally not integers, obtain the desired pixel value by interpolating between the nearest neighbors. For convenience, one might also generate a registered image B', such that corresponding pixels in image $A$ and $B^{\prime}$ can be accessed with the same indices.

The implementation of the above scheme is not quite straightforward, unless the relative distortions between $A$ and $B$ are small, .as in satellite images (5). In the example considered here, we used a pair of aerial photographs of mountainous terrain, taken at low altitude and with a wideangle lens (Figure 6). This causes severe local distortions, for the correction of which many control points and high order correction functions are needed.

The control points can be obtained by manually measuring the coordinates of visual landmarks such as road intersections and so forth, or, if we are more sophisticated, by using some local image matching technique such as correlation. Manual measurements are of course tedious, and provide control points that are, at best, randomly scattered about the image (Figure 6).

On the other hand, automatic local image matching offers convenience but is fraught with a number of difficulties such as computational load and "false fixed" (6). Figure 7 shows the results of a fast matching algorithm presently in development, and to be described at a later time. In this particular case, approximately $5 \%$ of the points are "false fixes", e.g. Incorrect control points that must be detected and corrected. 


\section{SEPT 1977}

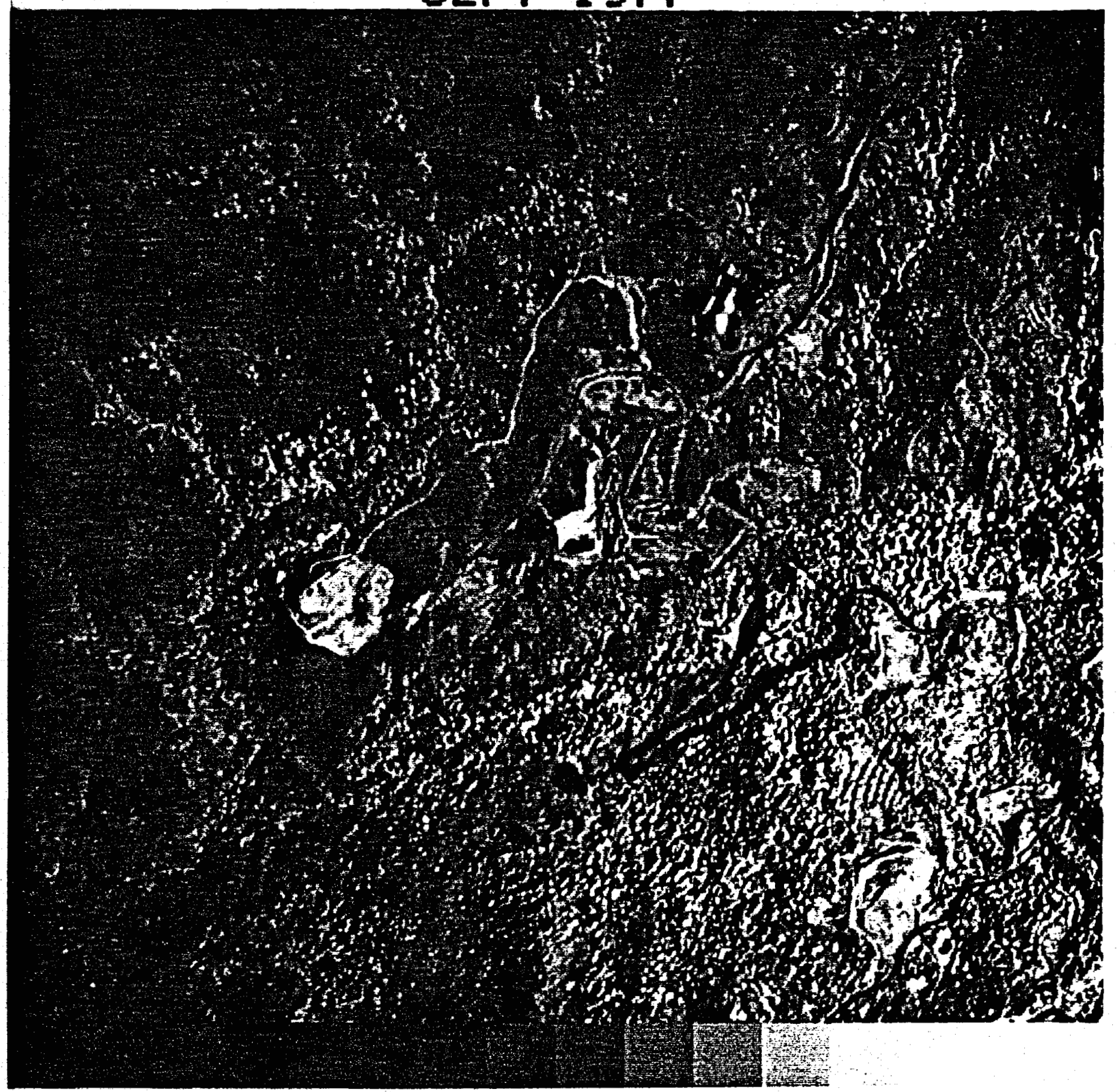

Figure 6a. Aerial photograph taken in Geysers, Calif of geothermal power generating site. This photograph was digitized and reproduced with the scanner of Figure 1 . 


\section{MARCH 1978 (REGISTERED)}

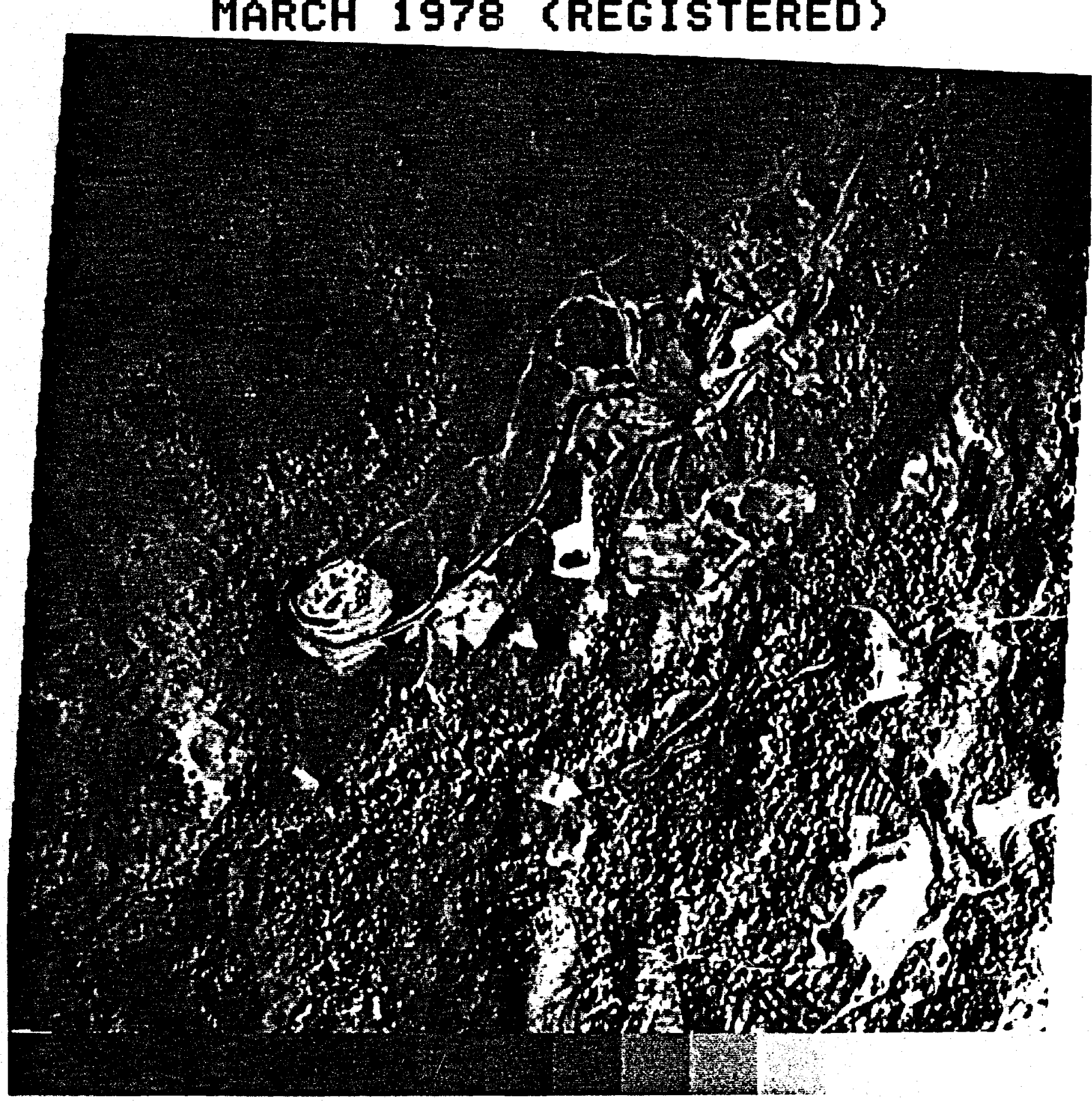

Figure 6b. Aerial photograph of same site, digitized and computer registered to match image of Figure $6 \mathrm{a}$. 
The next question is, given a set of control points, how should the functions $U(x, y)$ and $V(x, y)$ be determined? In keeping with the rubber sheet analogy, the solution would be to interpolate between the control points. If the number of points is large enough, as desired for accuracy, polynomial interpolation is numerically infeasible because the high order terms are very small. The alternative of local interpolation (bilinear, spline) is unfortunately impractical in two dimensions, unless the control points are available on a regular grid as in Figure 7 .

Pending further development of an automatic matching algorithm that provides such a set of points, we can approximate (instead of interpolate) the functions $U(x, y)$ and $V(x, y)$, under some error criterion. This is as if the rubber sheet of our analogy were too "stiff" to exactly accommodate all the distortions imposed by the control points. We can for instance approximate $U(x, y)$ and $V(x, y)$ with two dimensional polynomials of the form:

$$
\begin{aligned}
& U=a_{0}+a_{1} x+a_{2} y+a_{3} x^{2}+a_{4} y^{2}+a_{5} x y+\ldots \\
& V=b_{0}+b_{1} x+b_{2} y+b_{3} x^{2}+b_{4} y^{2}+b_{5} x y+\ldots
\end{aligned}
$$

whereby the coefficients $a_{0} \ldots a_{k}$ and $b_{0} \ldots b_{k}$ are obtained by inversion of the well known normal equations (5). This minimize the mean square errors

$$
\sum_{i=1}^{n}\left[U_{1}-U\left(x_{1}, y_{1}\right)\right]^{2}
$$

and

$$
\sum_{i=1}^{n}\left[v_{i}-v\left(x_{1}, y_{1}\right)\right]^{2}
$$



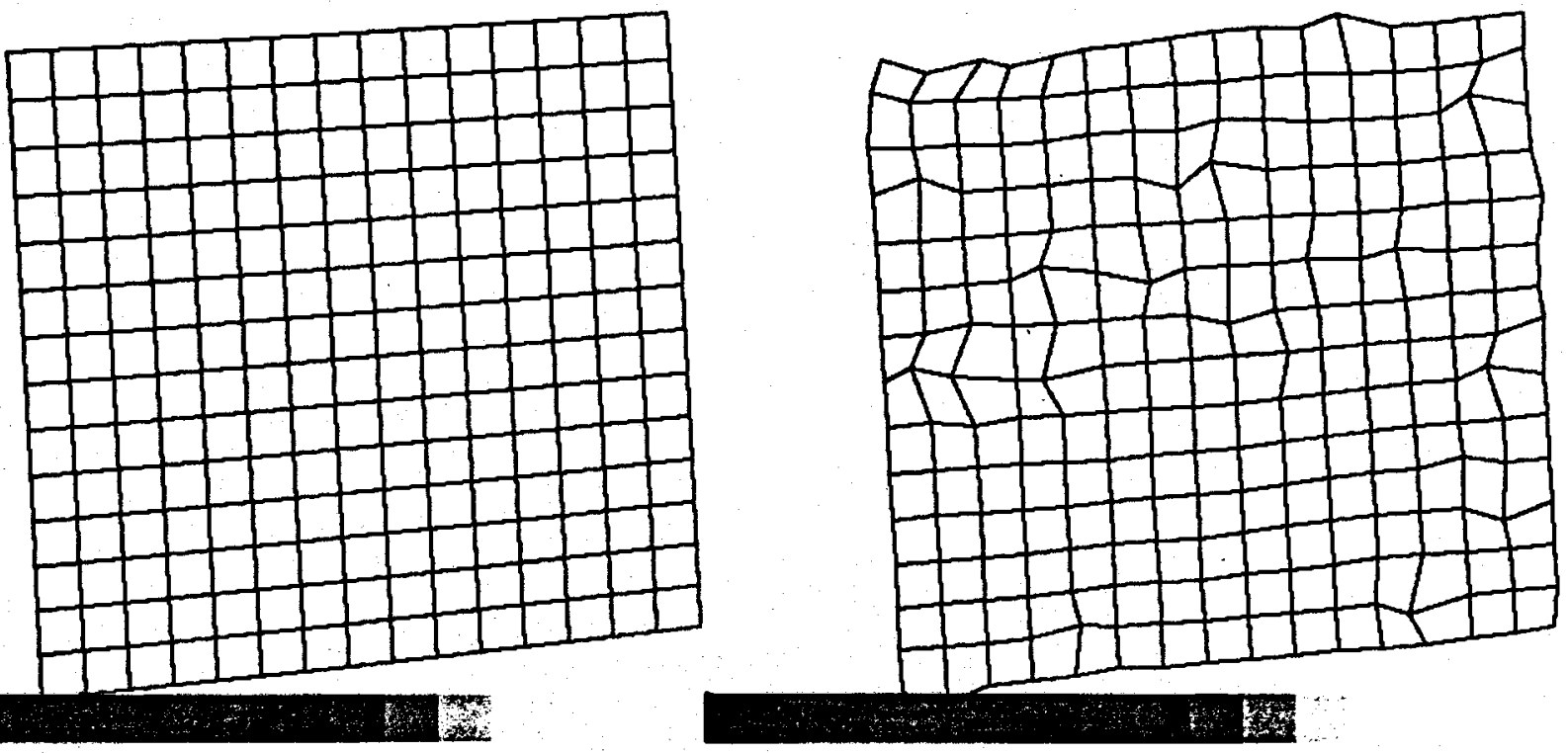

Figure 7. Mappings of rectangular grid in image $A$ onto image $B$ (see Figure 6). On the left, mapping obtained by polynomial approximation, on the right, mapping obtained by automatic matching algorithm. 
The question now is, how accurate is this approximation? In the example of Figure 7 we used second order polynomials (e.g. 12 coefficients shown in Table 1 ), and Table 2 shows the resulting errors between measurement and approximation at each landmark. As might be expected, the approximation is not equally accurate at all points, whereby the larger errors occur near the more abrupt changes in elevation. However, eighty percent of the errors are comparable to, and cannot be distinguished from the errors inherent in manual coordinate measurements $(+/-0.5$ pixel). Roughly speaking we can thus conclude that eighty percent of the image area is registered with an accuracy better than one pixel, a result comparable with work done on LANDSAT images (5).

In comparison, interpolative matching based upon automatic control point detection promises much better accuracies. Preliminary results indicate that the control points can be determined within an average of 0.15 pixels accuracy (8) and the algorithm begin developed is fast enough to permit detection of a large number of control points on a rectangular grid. Given such a grid, it is envisioned to use bilinear interpolation for the rubber sheet transformation with an overall registration accuracy better than 0.25 pixels. 


\section{Table 1}

Coefficients of Polynomial Approximation Function

$$
\begin{array}{ll}
a_{0}=-.29702026 \mathrm{D} \mathrm{02} & \mathrm{b}_{0}=-.21355850 \mathrm{D} 02 \\
\mathrm{a}_{1}=.10505432 \mathrm{D} \mathrm{01} & \mathrm{b}_{1}=-.27915959 \mathrm{D}-01 \\
\mathrm{a}_{2}=.79509398 \mathrm{D} \mathrm{01} & \mathrm{b}_{2}=-.12079401 \mathrm{D} \mathrm{01} \\
\mathrm{a}_{3}=-.94335008 \mathrm{D}-06 & \mathrm{~b}_{3}=-.28316191 \mathrm{D}-04 \\
a_{4}=-.22970985 \mathrm{D}-04 & \mathrm{~b}_{4}=-.19246225 \mathrm{D}-03 \\
a_{5}=-.13767786 \mathrm{D}-04 & \mathrm{~b}_{5}=-.14563588 \mathrm{D}-03
\end{array}
$$

Table 2

Absolute Errors of Polynomial Approximation (in Pixels)

$$
\text { (Mean square error }=0.765 \text { pixels) }
$$

$\begin{array}{cccc}\text { Control Point } & \text { Error } & \text { Control Point } & \text { Error } \\ 1 & .59 & 13 & .26 \\ 2 & .58 & 14 & .15 \\ 3 & 1.47 & 15 & .94 \\ 4 & .95 & 16 & .80 \\ 5 & 2.52 & 17 & .82 \\ 6 & .36 & 18 & .18 \\ 7 & .48 & 19 & 2.56 \\ 8 & .34 & 20 & .54 \\ 9 & 1.02 & 21 & .17 \\ 10 & .15 & 22 & 1.46 \\ 11 & .26 & 23 & .57 \\ 12 & .43 & & \end{array}$




\section{THE GEYSER GEOTHERMAL PROJECT.}

of the known geothermal resource areas (KGRA's) in the United States, the Geysers in northern California have a particularly attractive property: the geothermal heat can be captured in the form of pressurized hot steam, which can easily be harnessed to generate electricity. As a result, a score of steam power plants have been constructed and operate during the last decade, with a presently installed capacity of approximately eight hundred megawatts. The environmental impact of these installations has been small so far, upon a region of low population and land of low utilization, except for an intensification of the naturally present smell of hydrogen sulfide.

Under the present government priorities however, extensive further developments are considered notably towards the neighboring wine producing counties of Napa and Sonoma. At the same time, new emission abatement techniques are being developed, which should solve the hydrogen sulfide problems. In order to assure an environmentally sound development, DOE has sponsored comprehensive studies of pertinent environmental factors such as the dispersion of exhaust drifts, the impact on vegetation, seismicity, ground water and so forth. In the present phase of this project, two sites had been photographed adequately for the application of our computer change detection technique: a steam generating plant (Figure 6) and a new well drilling site (Figure 8 ).

The above sites have been photographed on color-infrared film in September of 1977 and March of 1978, using a Haselblatt camera and a wide angle lens. Due to the low altitude (5000 feet), the wide angle lens and the roughness of the terrain, registration was particular difficult. 


\section{SEPT 1977}
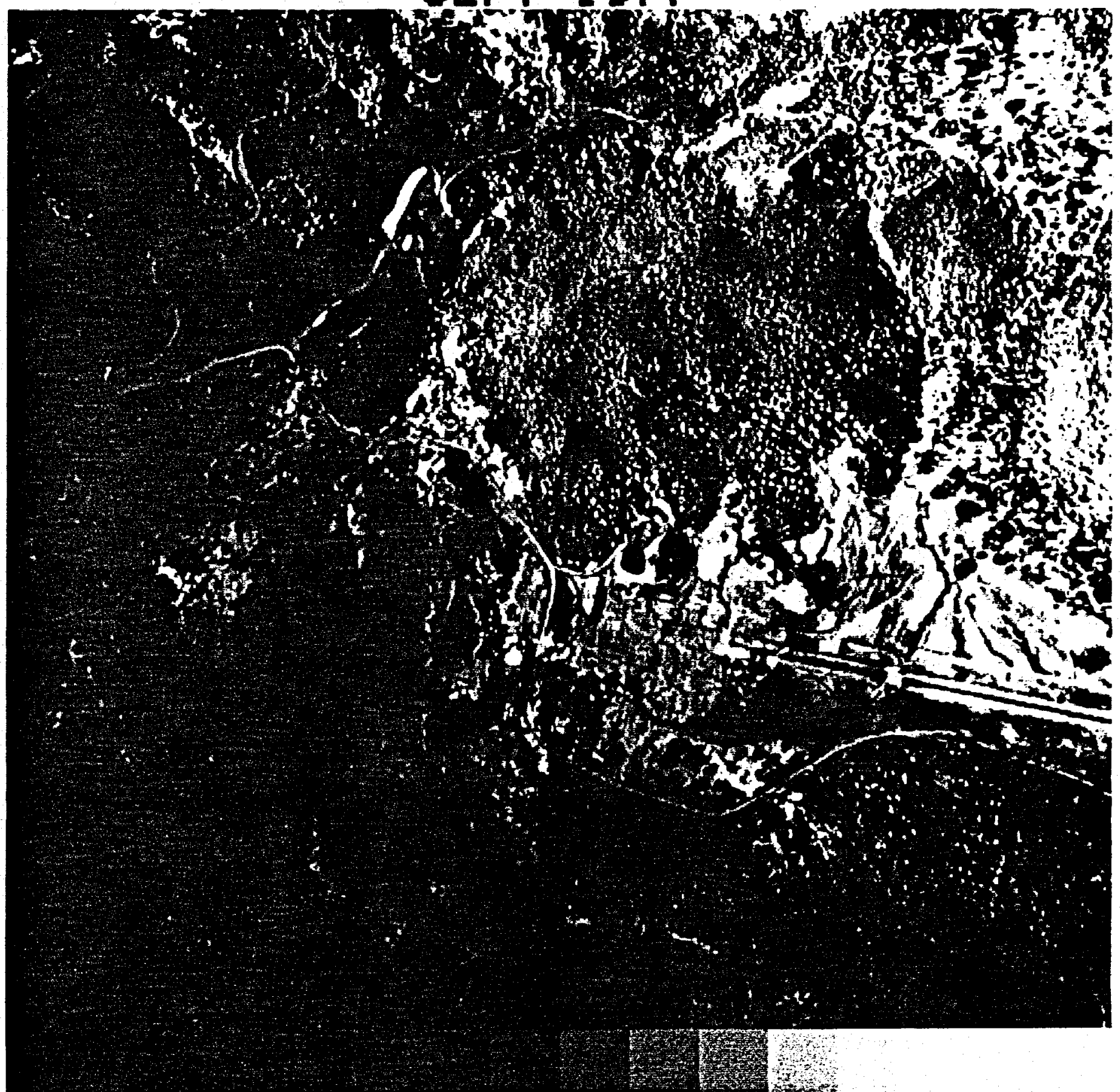

Figure 8a. Aerial photograph of geothermal drilling site, taken in the Geysers, Calif. in September 1977, and digitized on scanner of Figure 1 . 


\section{MARCH 1978 (REGISTERED)}

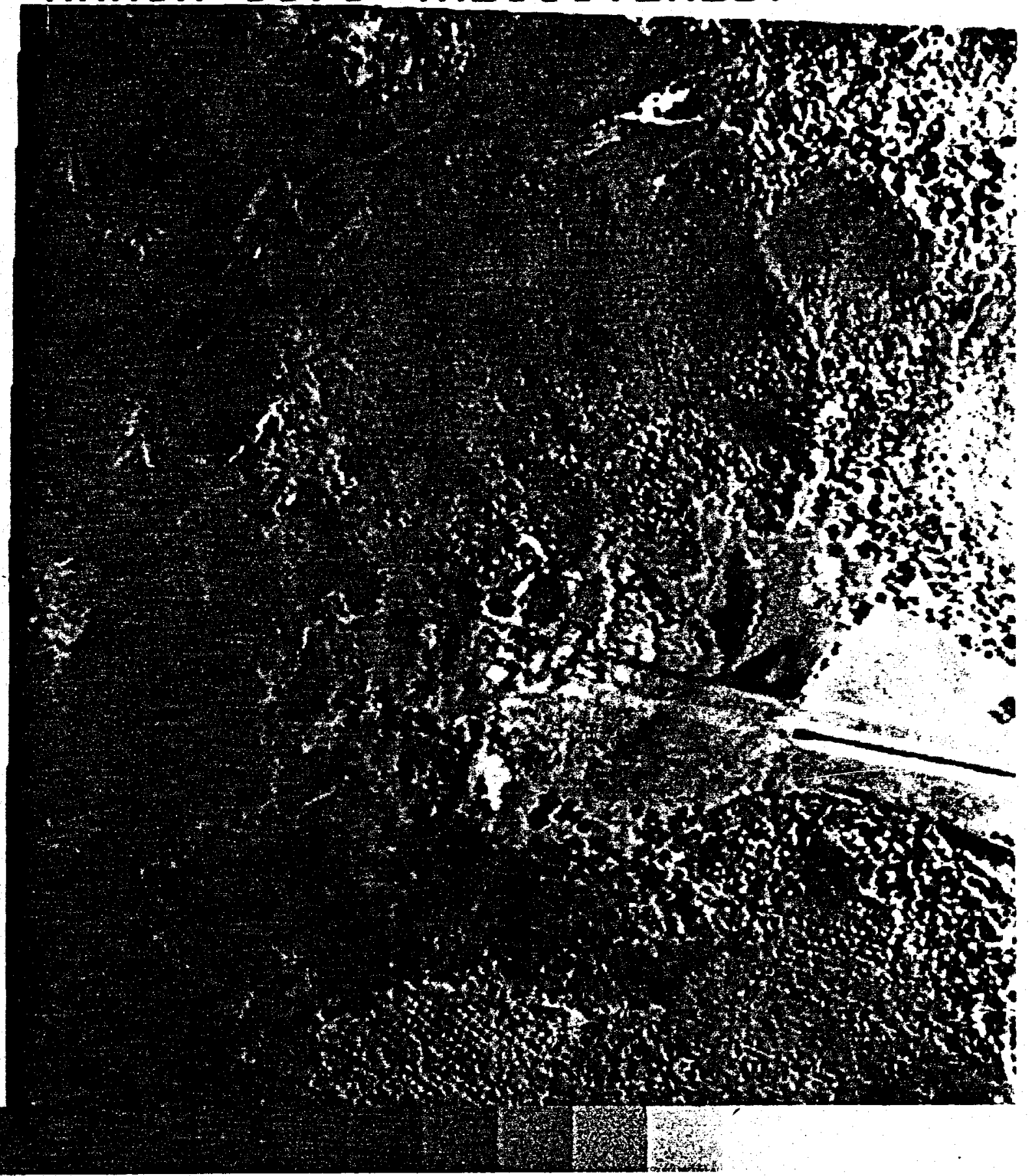

Figure 8b. Aerial photograph of geothermal drilling site, taken in the Geysers, Calif. in March 1978, and registered to match Figure $8 a$. 
- Figure 9 shows the "change image" obtained from the pair of views of Figure 6 . This image reveals an interesting and otherwise unnoticeable environmental effect, namely an increased growth of grasses in the immediate vicinity of the cooling tower (Figure 9 arrow). This is presumably due to the artificial micro-climate caused by evaporative cooling (Increased temperature and humidity). However, a decreased foliage density is observed in the bushes present on the higher slopes surrounding the cooling tower. The reason is that these bushes are deciduous and that new foliage had not developed yet at the time of the second overflight.

This case highlights the issues of interpreting the change imagery, which requires knowledge about the ecosystem at hand: characteristics of the species, seasonal effects and so forth. Ground truth information is thus as essential here as in any other remote sensing endeavor.

Figure 10 shows the "change image" obtained from the pair of views of Figure 8 . This image covers two drilling sites, on which various infrastructure operations have taken place during the interval of time between the overflights: grading, construction drilling and vegetation. Examination of the change image clearly reveals the effects of these operations, particularly the vegetation of the graded areas. It is pointed out however, that these sites have not had activities resulting in atmospheric emissions (except perhaps dust) and that we do not notice any suspect changes, as might be expected. 


\section{DIFFERENCE IMAGE}

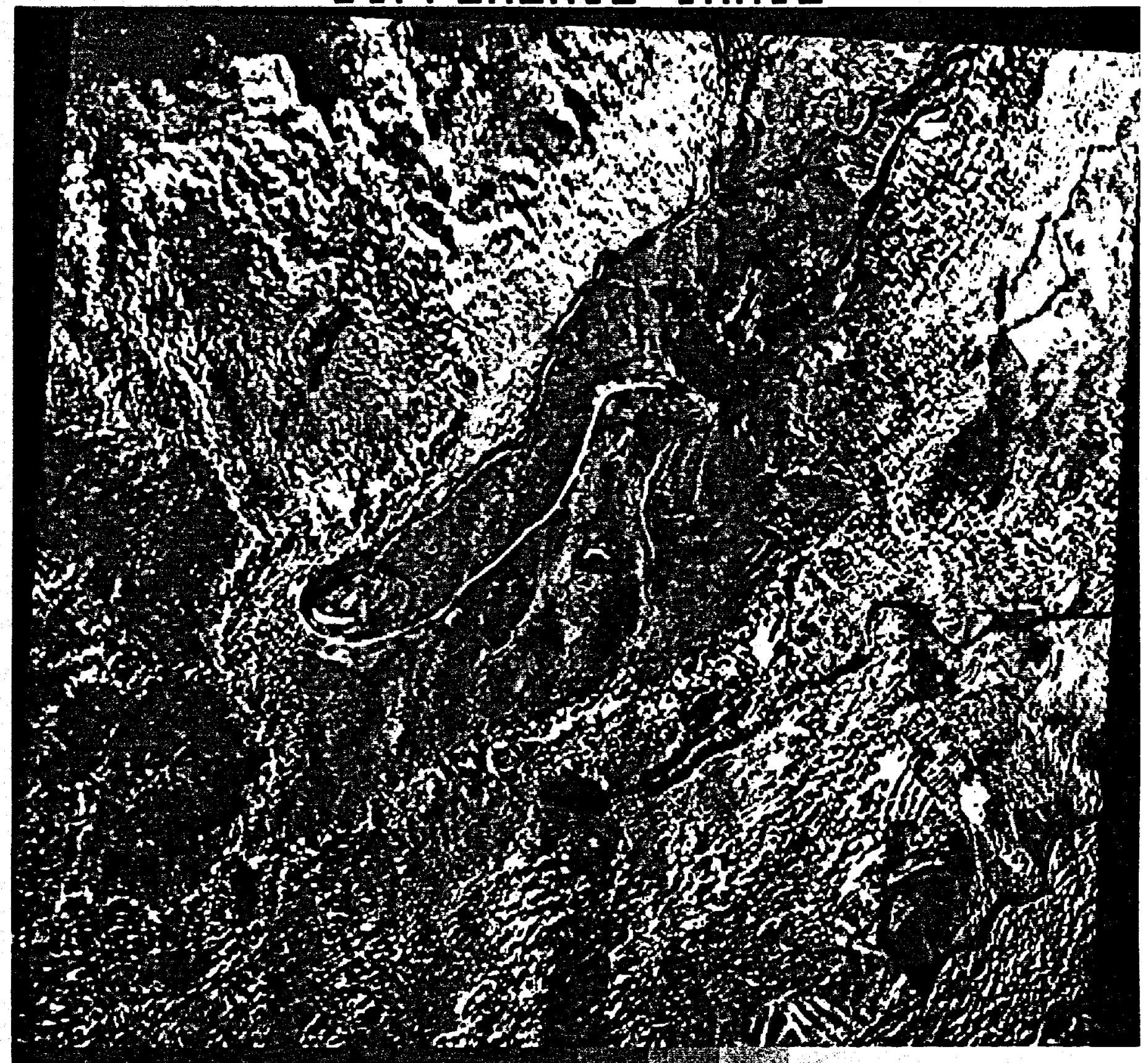

Figure 9. Change image obtained from pictures of Figure 6. See text for comments. 


\section{DIFFERENCE IMAGE}

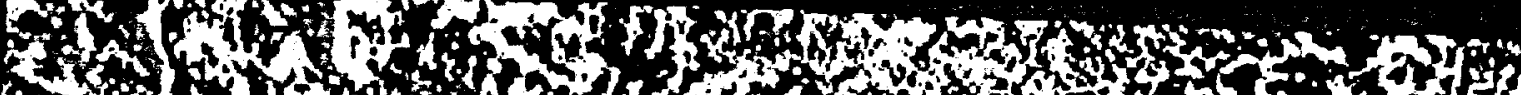

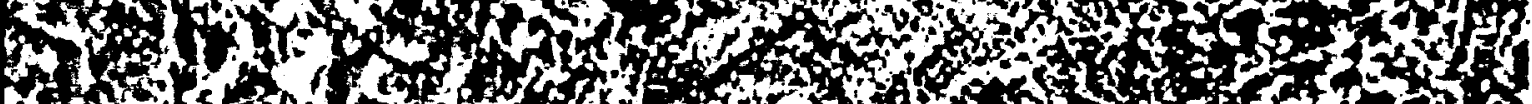

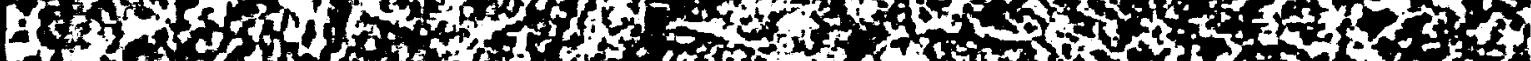

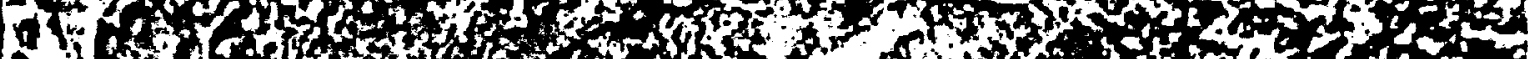

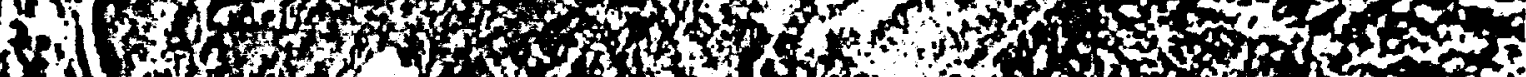

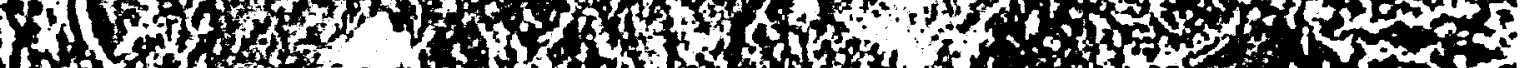

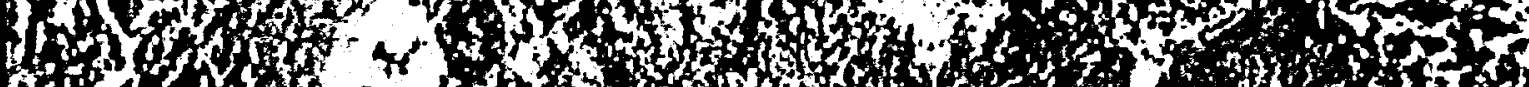

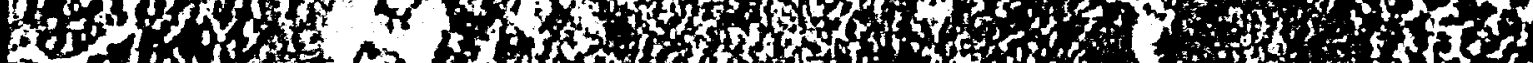

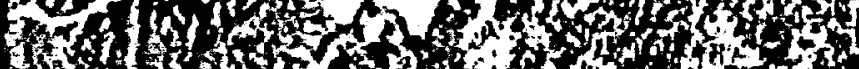

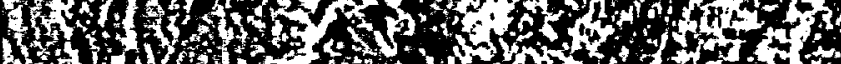

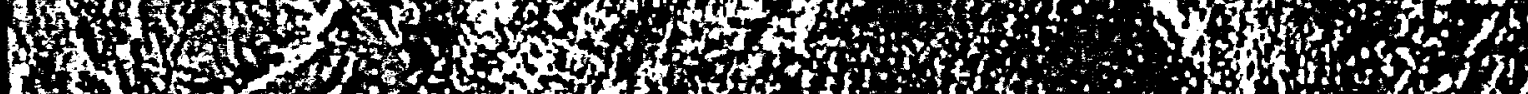

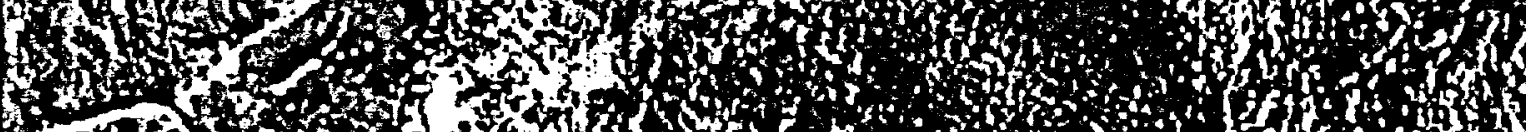

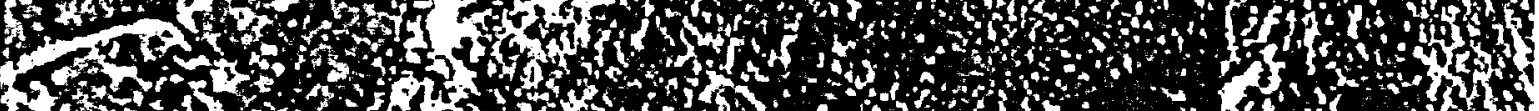

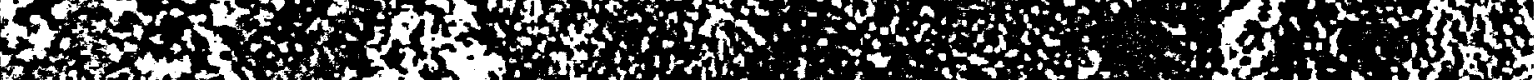

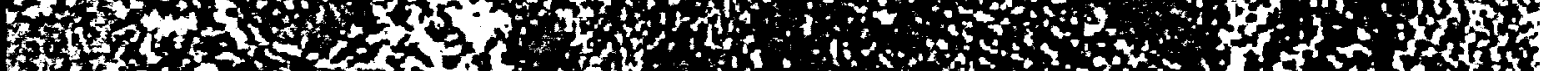

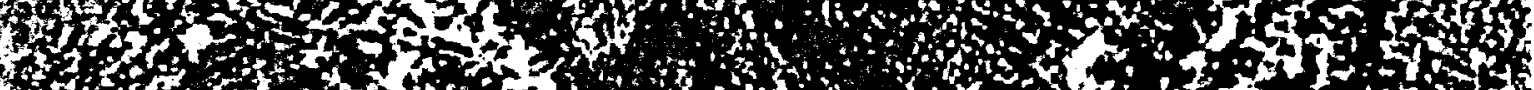

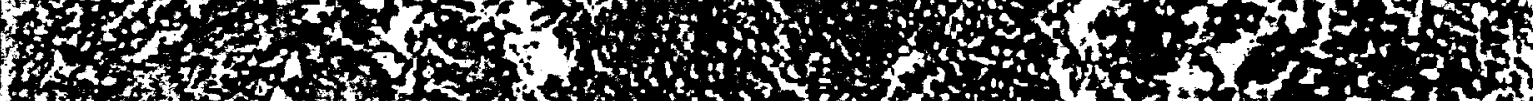

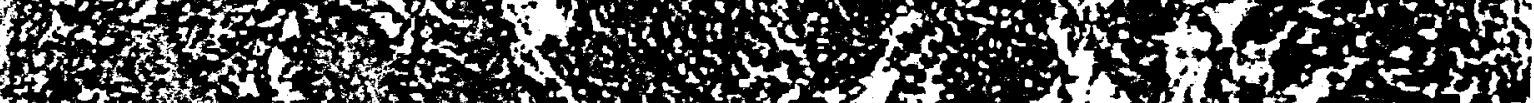

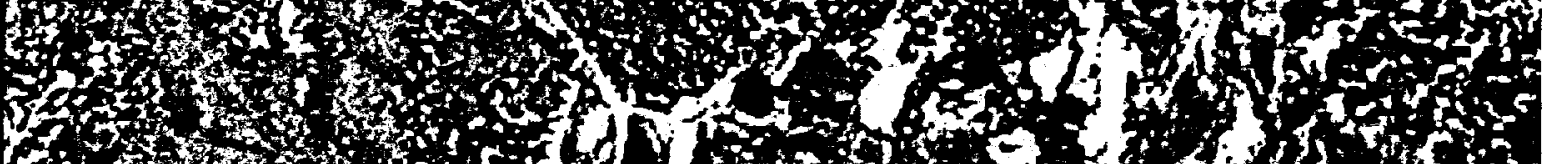

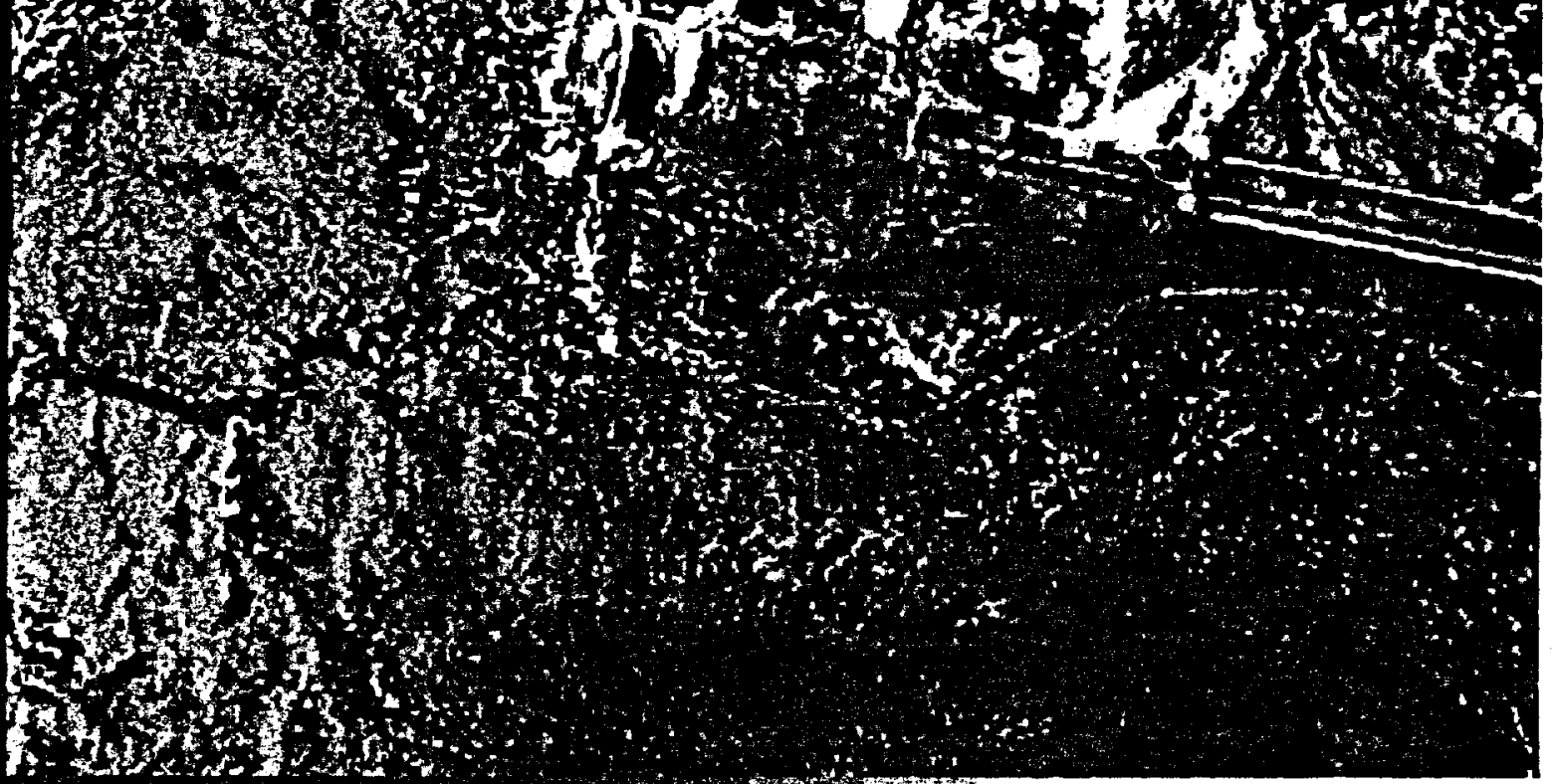

Figure 10. Change image

generated from the pictures of Figure $8 a$ and Figure $8 b$.

Notice contruction and

grading areas (see text). 


\section{CONCLUSIONS AND OUTLOOK.}

The above study permits several conclusions about the role of remote sensing in the context of environmental assessment studies.

Most significant perhaps is the broad overall coverage of sites and surroundings obtained by aerial data acquisition. Compared. to the more traditional investigation conducted on the ground, this permits to scrutinize much larger areas at low cost. Consequently, effects that are characterized by minute changes affecting large areas are more likely to be detected by remote sensing, before profound ecological changes have taken place.

The change detection technique developed here is particularly interesting, because it is extremely sensitive to very minute and otherwise invisible changes that can constitute an early warning for impending environmental problems.

An additional and significant advantage of this change detection technique is that the results presented in pictorial form are easily understandable and interpretable by experts of other fields involved in environmental assessment studies. This point is essential since such studies hinge on a good communication and interaction between the different disciplines concerned. It should in fact be stressed that remote sensing work needs the input provided by investigators on the ground, and that it should by no means replace such studies. Quite to the contrary, a most fruitful synergy is predictable: whereas remote sensing results are corroborated by ground truth information, at the same time, ground studies can be more adequately planned and directed by use of the remotely sensed data. 
Although it is early to draw final conclusions as to all the aspects of the role of remote sensing in environmental assessment studies, it is perfectly clear that a powerful tool has been made available at a very low cost. The experience gathered during our collaboration with the ecologists at the Lawrence Livermore Laboratory and UCLA underscore the usefullness of this tool, chiefly change detection, which we are continuously improving as a part of our research program. Some of the technical problems that are currently being studied regard possible artifacts such as might be caused by different lighting conditions, atmospheric conditions, variations in photographic processing (or calibration of multi-spectral scanners), etc. Variations in lighting angle between the two views pose perhaps the most severe problem, particularly in mountainous terrain, and if the images are taken months apart. This is because the sun angle changes, causing some slopes to receive more illumination and others: less. The effect can be reduced somewhat but not eliminated completely, by adjusting the time of the image acquisition. One approach to overcome the problem would be to determine, from the terrain elevations, the orientation of small areas on the ground with respect to the incident illuminations. Then, using some model of angular reflectance, determine the reflectivity of the ground from the relative brightness measured on the picture, and correct for lighting angle.

Looking beyond change detection is the increased machine assistance in the analysis and characterization of the changes. Using multispectral data, it is effectively possible to classify the "before" image into regions that have specific characteristics, such as the presence of certain plant species. Then, the changes detected can be compared with the changes expected in each specie, and abnormal changes flagged. This idea is being investigated. 


\section{ACKNOWLEDGEMENTS.}

The authors wish to thank the Department of Energy and the Lawrence Livermore Laboratory who have made this work possible, particularly Paul Phelps and Dean Cornett who have patiently helped us define and conduct this program. Further, the great help and enthusiasm of Dr. Romney of UCLA and Dr. Rhoads of EG \& $G$ has been central to the successes obtained. Finally, our thanks to EG \& $G$ in Las Vegas which has provided the aerial photographs. 


\section{REFERENCES.}

1. J.C. Liverman, "Imperial Valley Environmental Program", Hearings before the U.S. House of Representatives, September 1977 .

2. P.A. Murtha, "Remote Sensing and Vegetation Damage", Photogrametric Engineering and Remote Sensing, Vol.44, No-9, pp. 1147-1158, September 1978.

3. W. Frei, "Image Enhancement by Histogram Hyperbolization", Computer Graphics and Image Processing, Vol.6, pp. 286294,1977 .

4. T.N. Cornsweet, "Visua1 Perception", Academic Press, New York, 1970.

5. T. Kaneko, "Evaluation of Landsat Image Registration Accuracy", Photogrammetric Engineering and Remote Sensing, Vol. 42, pp. 1285-1299, October 1976.

6. W. Frei, T. Shibata, C. Chen, "Fast Image Matching Based on Edge Features", in preparation.

7. See, for example, Arden \& Astile, "Numerical Algorithms", Addison-Wesley, 1970.

8. T. Shibata, W. Frei, G.C. Huth, "Image Registration with Fractional Pixel Accuracy", Fourth International Joint Conference on Pattern Recognition, Kyoto, Japan, November 1978 .

9. W. Frei, "Image Enhancement by Histogram Hyperbolization", Computer Graphics and Image Processing, Vol. 6, pp . 286294, 1977. 